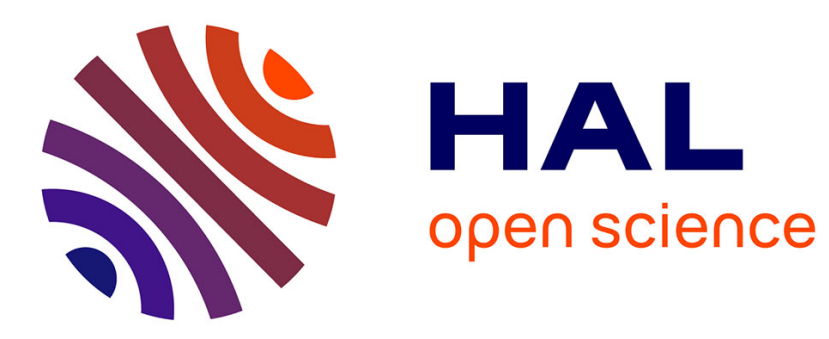

\title{
Identification of the Inspection Specifications for Achieving Zero Defect Manufacturing
}

Foivos Psarommatis, Dimitris Kiritsis

\section{To cite this version:}

Foivos Psarommatis, Dimitris Kiritsis. Identification of the Inspection Specifications for Achieving Zero Defect Manufacturing. IFIP International Conference on Advances in Production Management Systems (APMS), Sep 2019, Austin, TX, United States. pp.267-273, 10.1007/978-3-030-30000-5_34 . hal-02419228

\section{HAL Id: hal-02419228 \\ https://hal.inria.fr/hal-02419228}

Submitted on 19 Dec 2019

HAL is a multi-disciplinary open access archive for the deposit and dissemination of scientific research documents, whether they are published or not. The documents may come from teaching and research institutions in France or abroad, or from public or private research centers.
L'archive ouverte pluridisciplinaire HAL, est destinée au dépôt et à la diffusion de documents scientifiques de niveau recherche, publiés ou non, émanant des établissements d'enseignement et de recherche français ou étrangers, des laboratoires publics ou privés.

\section{(c)(1)}

Distributed under a Creative Commons Attribution| 4.0 International License 


\title{
Identification of the inspection specifications for achieving Zero Defect Manufacturing
}

\author{
Foivos Psarommatis*1 and Dimitris Kiritsis ${ }^{1}$ \\ ${ }^{1}$ École polytechnique fédérale de Lausanne, ICT for Sustainable Manufacturing, EPFL SCI- \\ STI-DK, Lausanne, Switzerland \\ foivos.psarommatis@epfl.ch
}

\begin{abstract}
The contemporary manufacturing landscape is characterized by increased volatility shortened product life cycles and increased degree of product customization. Manufacturing companies are continuously facing the challenge of operating their manufacturing processes and systems in order to deliver the required production rates of high quality products, while minimizing the use of resources. They can achieve this with a concept named Zero Defect Manufacturing. This concept implies that inspection is performed to all the parts and therefore they can achieve zero defects. The problem is that inspection can be either time consuming process or a very expensive process. The goal of the current research work is a methodology for the identification of the acceptable inspection specification in order for the production system to stay efficient and at the same time produce non-defected products. In other words the outcome of this paper will be a set of maps that depicts which can be the acceptable inspection characteristics such as inspection time and inspection cost.
\end{abstract}

Keywords: Zero Defect Manufacturing, Inspection Time, Inspection Cost, Inspection specification, Defect Detection.

\section{$1 \quad$ Introduction \& State of the Art}

The contemporary manufacturing landscape is characterized by increased volatility shortened product life cycles and increased degree of product customization. Further to that the required quality by the customers has been higher than ever and therefore, manufacturers in order to stay competitive should adapt to these changes and start adopting new strategies that will allow them to achieve higher product qualities keeping costs as low as possible and at the same time respecting the due dates. The minimization of cost is a major consideration for all manufacturing industries and this is directly related with the product's quality. In addition, the product's quality is directly related with the inspection policy that has been selected.

One of the strategies that can take into account and provide high quality parts at low costs is called Zero Defect Manufacturing (ZDM), which has as a goal of eliminating with various ways defected parts in the production, but it is not an easy task [1]. As described in [2][3] there are four main strategies for implementing ZDM the Detect, 
Prevent, Predict and Repair of a defect. The most critical is the detection strategy because all the other strategies are relying on the data collected during the detection step.

It is common that in most of the manufacturing systems the quality testing of the product is performed at the end the process chain [4]. This is happening for separating the defective parts from the acceptable in order to treat them with different way. ZDM imposes that part inspection should happen in multiple stages [5] and not only at the end of the process chain.

The detection of a defect is a very important step of the manufacturing process [6]. However, there is no clear approach of what would be the acceptable specification of the inspection points, relatively to the total processing time and total product cost. Therefore, this paper aims to develop a methodology for defining what should be the acceptable inspection characteristics in order for the manufacturers to stay competitive and be able to achieve Zero Defect Manufacturing by inspecting all of the parts.

The majority of the literature deals with the development of effective and accurate inspection and monitoring technics without concerning the implications that may have to the actual production [5]. For that reason there is the need for integrated approaches to jointly optimize, at system level, maintenance, quality and production control strategies, in order to avoid local improvements that can bring minor, or even detrimental, effects at system level [7].

Genta et al. developed a method based on which he was able to predict the probability of defect occurrence relevant to each process step and that way they could plan an effective inspection [8]. Sarkar created an economic production quantity model where the process is deteriorated based on production of defective products. To avoid the higher cost of inspection, product inspection policy was performed instead of full inspection policy where the product inspection policy was not error free [9]. Mohammadi et al. developed a mathematical model for deteriorating process representing the expected total cost to obtain the optimal solution. The aim of this research was to determine the production period length and inspection policy such that the expected total cost is minimized [10]. In chapter 2, the mathematical formulation of the current work is presented. Then in chapter 3, the implementation of the proposed method to an industrial case is performed and finally in the conclusion section, the paper is summarized.

\section{Proposed methodology}

Currently, there are numerous of different inspecting technologies with different characteristics each, and the implementation of inspection points on every manufacturing stage is not possible due to cost and time constrains. Therefore, manufacturers need a tool that could indicate what could be the acceptable combinations between inspection time and inspection cost based on the total processing time and total product cost. This methodology should be applied to the critical points for selecting the most appropriate inspection equipment in order to be able to inspect all the products and that way guaranty $100 \%$ defect free order.

The current methodology aims to assist manufacturers in the process of designing, re-designing, or adjusting manufacturing systems to new products in order to determine 
what inspection equipment they need. The method is quite simple but the outcome has a significant impact to the achievement of ZDM. Two measures were used for the initialization of the process, the Estimated Product Cost (EPC) and the Estimated Production Time (EPT), which includes all the costs and all the times for the manufacturing and inspecting the product, accordingly. Both measures consists the theoretical - nominal values of these product parameters and consider only the manufacturing of the product from start to finish without any inspection. Having those parameters, we define two ratios the Inspection Time Ratio (ITR) and the Inspection Cost Ratio (ICR) that are described by formulas (1) and (2). The ratio approach selected in order to provide a relative indicator that shows how much extra time or cost is needed for the inspection having as reference the nominal values.

$$
I T R=\frac{\text { Inspection Time }}{E P T}(1) \quad I C R=\frac{\text { Ispection Cost }}{E P C}(2)
$$

ITR and ICR take values between 0 and 1 . ITR is an independent value whereas the ICR includes the calculated Inspection Time. The goal is to find all the sets of the two ratios that corresponds to acceptable inspection characteristics. Those sets will be used in order to create a map of the acceptable inspection characteristics in order to inspect all the products and that way achieve Zero Defect Manufacturing.

\subsection{Performance Indicators used for the simulation}

Three different PIs were used for the comparison of the different scenarios (SC): a) the tardiness of the order $(\mathrm{OT}), \mathrm{b})$ the quality of the solution $(\mathrm{OQ})$, measuring how many defected parts were at the end and c) the actual product cost (PC). The PC should not be mixed with the EPC. PC is the actual product cost as it was calculated after the simulation. Equations 3, 4 and 5 present the formulas that the KPIs are calculated. Those values were normalized and weighted and summed to one value which corresponds to the quality of the solution [11], [12].

$$
\begin{gathered}
\text { OT }=\max (\text { DueDate }- \text { Makespan }, 0) \\
P C=\sum \text { RawMaterialsC }+\sum \text { operationalC } \\
O Q=\frac{\text { TotalProductsMade }- \text { DefectedProducts }}{\text { TotalProductsMade }}
\end{gathered}
$$

\section{Experimental results}

The use of the proposed method in an Industrial scenario will be described in this chapter. A dynamic scheduling tool was used for the simulation which is described in [3]. In addition, the product used for the simulations is composed out of 13 processes and the corresponding bill of processes $(\mathrm{BoP})$ is shown in the right side of Table 1 . The simulation was including only a part of the factory, and more specifically 10 machines, configured as "open shop" [13]. In addition, the simulation was performed for 3000 
parts with a specific due date. In addition, the simulations were considering product inspection at the final manufacturing stage. The inspection parameters were defined according to the methodology presented in chapter 2 . The left side of Table 1 depicts the scenarios that were defined for the simulations with the inspection times and costs used for each one. In addition, the product under investigation has $\mathrm{EPC}=341.2 €$ and EPT=108.2 min. Having these values and using the formulas (1) and (2), we were able to calculate the corresponding Inspection times and Costs.

Table 1. Experiment Inspection scenarios \& product Bill of Processes (BoP)

\begin{tabular}{|c|c|c|c|c|c|c|}
\hline SC & ITR & ICR & $\begin{array}{l}\text { Inspection } \\
\text { Time (min) }\end{array}$ & $\begin{array}{c}\text { Inspection } \\
\text { cost }(€)\end{array}$ & $\begin{array}{c}\text { Inspection ma- } \\
\text { chine cost } \\
(€ / \text { hour })\end{array}$ & Product BoP \\
\hline 1 & 0.1 & 0.1 & 10.82 & 34.12 & 189.2052 & \multirow{16}{*}{ 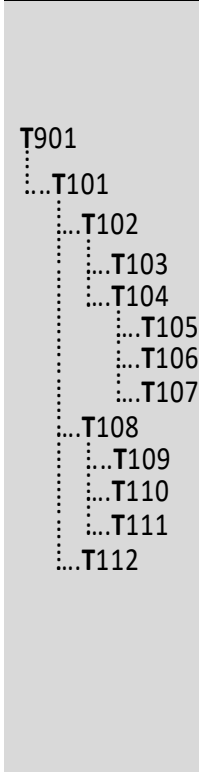 } \\
\hline 2 & 0.3 & 0.3 & 32.46 & 102.36 & 189.2052 & \\
\hline 3 & 0.5 & 0.5 & 54.1 & 170.6 & 189.2052 & \\
\hline 4 & 0.7 & 0.7 & 75.74 & 238.84 & 189.2052 & \\
\hline 5 & 0.1 & 0.3 & 10.82 & 102.36 & 567.6155 & \\
\hline 6 & 0.3 & 0.5 & 32.46 & 170.6 & 315.342 & \\
\hline 7 & 0.5 & 0.7 & 54.1 & 238.84 & 264.8872 & \\
\hline 8 & 0.7 & 0.1 & 75.74 & 34.12 & 27.02931 & \\
\hline 9 & 0.1 & 0.5 & 10.82 & 170.6 & 946.0259 & \\
\hline 10 & 0.3 & 0.7 & 32.46 & 238.84 & 441.4787 & \\
\hline 11 & 0.5 & 0.1 & 54.1 & 34.12 & 37.84104 & \\
\hline 12 & 0.7 & 0.3 & 75.74 & 102.36 & 81.08793 & \\
\hline 13 & 0.1 & 0.7 & 10.82 & 238.84 & 1324.436 & \\
\hline 14 & 0.3 & 0.1 & 32.46 & 34.12 & 63.06839 & \\
\hline 15 & 0.5 & 0.3 & 54.1 & 102.36 & 113.5231 & \\
\hline 16 & 0.7 & 0.5 & 75.74 & 170.6 & 135.1466 & \\
\hline
\end{tabular}

All the scenarios were compared among each other and with a benchmark scenario ("B") in which inspection was performed every 100 parts, but the same number of defects were introduced during the simulation. Four different set of weights were used at the performance indicators (PI), in order to demonstrate the different requirements that each manufacturer has. The results from the simulations are illustrated in Fig. 1. It can be seen that in the three out of four weight sets the quality of the benchmark scenario is lower than 0.66 , only in the last weight scenario that Order Quality is not that important $(0.2)$ benchmark is close to the best with $9.52 \%$ relative difference from the best of the set.

The next step is to use the results from the experiments, illustrated in Fig. 1 and create the maps for the acceptable inspection characteristics. For each weight set the 16 scenarios' values were compared with the benchmark and if they were above the benchmark then this value is acceptable and should be considered to the corresponding map. The benchmark scenario is the current situation on the shop floor and the current study 
aims to improve the performance of the system in terms of order quality but keeping production cost and makespan as low as possible.

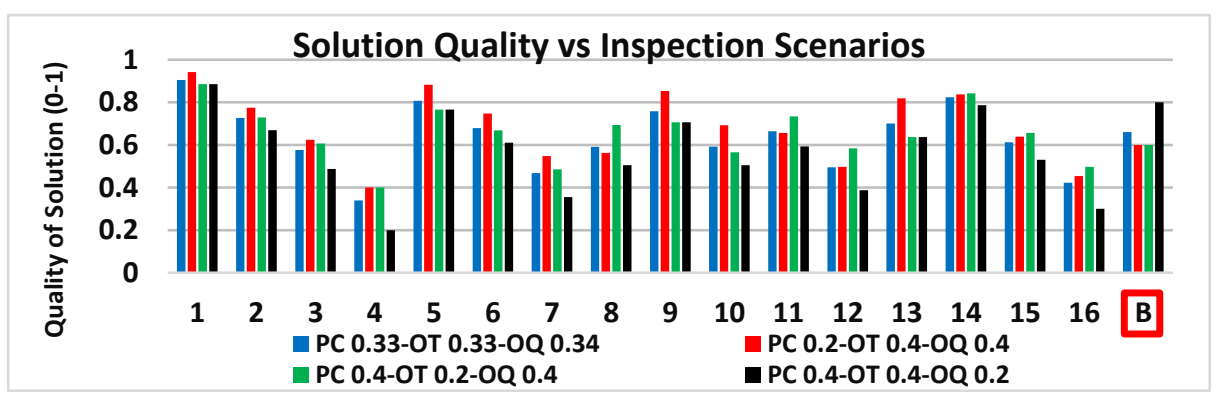

Fig. 1. Inspection Scenarios and Benchmark solutions quality

Then all the revealed points were put in a common graph, Fig. 2 and the area that is below the marked line depicts the acceptable inspection combinations in terms of inspection time and inspection equipment operational cost. The weight scenario with the least possibilities is the scenario in which quality is not that important. This case is not presented in Fig. 2 because only one scenario was better than the benchmark test, scenario 1 , which imposes very quick and low cost inspection device.
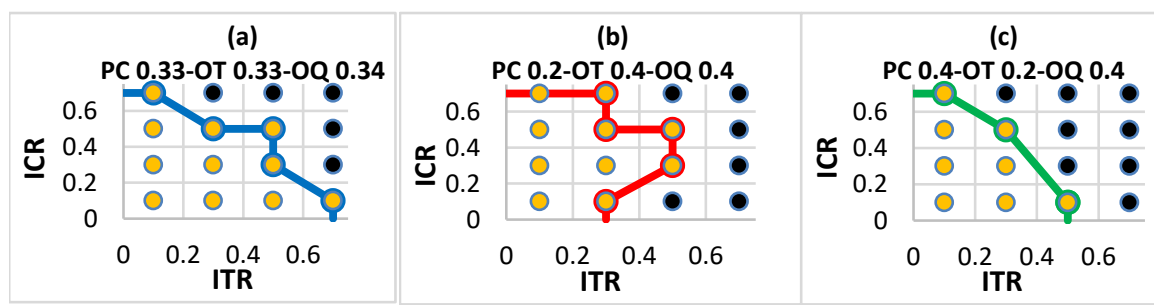

Fig. 2. Inspection Specification Map for different criteria weights

\section{Conclusions and future work}

This paper provides a method identifying the acceptable inspection parameters in order to select the appropriate inspection equipment and efficiently inspect all the produced parts and achieve ZDM. In addition, the results were split into four categories, each category was considering different weights to the PIs. It was observed and expected, that the inspection scenarios that had low inspection time and low inspection cost, were common points to three out of four maps. It is obvious that the cheaper and the faster the inspection point the better it is, but when it comes to inspection this combination is not always the case. Therefore, manufactures need methods like the above mentioned in order to be able to decide if an inspection point would be efficient or not.

Future work will focus on the study of multiple inspection point across the manufacturing of a product and simulating the entire shop floor. Further to that, the simulation of multiple product will be investigated as well as different shop floors set ups. In this industrial case, the shop floor was set up as an "open shop" configuration. 


\section{Acknowledgment}

The presented work presented supported by the project Z-Fact0r, an EU H2020 project under grant agreement No 723906. The paper reflects the authors' views and the Commission is not responsible for any use that may be made of the information it contains.

\section{References}

1. S. Ferretti, D. Caputo, M. Penza, and D. M. D’Addona, "Monitoring systems for zero defect manufacturing," Procedia CIRP, vol. 12, pp. 258-263, 2013.

2. F. Psarommatis, G. May, P.-A. Dreyfus, and D. Kiritsis, "Zero defect manufacturing: state-of-the-art review, shortcomings and future directions in research," Int. J. Prod. Res., vol. 7543, pp. 1-17, 2019.

3. F. Psarommatis and D. Kiritsis, "A Scheduling Tool for Achieving Zero Defect Manufacturing (ZDM): A Conceptual Framework," Springer, Cham, 2018, pp. 271-278.

4. W. Klippel, "End-Of-Line Testing," in Assembly Line - Theory and Practice, InTech, 2011.

5. F. Eger et al., "Zero defect manufacturing strategies for reduction of scrap and inspection effort in multi-stage production systems," Procedia CIRP, vol. 67, pp. 368-373, 2018.

6. C. Iglesias, J. Martínez, and J. Taboada, "Automated vision system for quality inspection of slate slabs," Comput. Ind., vol. 99, pp. 119-129, Aug. 2018.

7. M. Colledani et al., "Design and management of manufacturing systems for production quality,” CIRP Ann., vol. 63, no. 2, pp. 773-796, Jan. 2014.

8. G. Genta, M. Galetto, and F. Franceschini, "Product complexity and design of inspection strategies for assembly manufacturing processes," Int. J. Prod. Res., vol. 56, no. 11, pp. 4056-4066, 2018.

9. B. Sarkar and S. Saren, "Product inspection policy for an imperfect production system with inspection errors and warranty cost," Eur. J. Oper. Res., vol. 248, no. 1, pp. 263-271, Jan. 2016.

10. B. Mohammadi, A. A. Taleizadeh, R. Noorossana, and H. Samimi, "Optimizing integrated manufacturing and products inspection policy for deteriorating manufacturing system with imperfect inspection," J. Manuf. Syst., vol. 37, pp. 299-315, Oct. 2015.

11. D. Mourtzis, M. Doukas, and F. Psarommatis, "A multi-criteria evaluation of centralized and decentralized production networks in a highly customer-driven environment," CIRP Ann. - Manuf. Technol., vol. 61, no. 1, pp. 427-430, 2012.

12. D. Mourtzis, M. Doukas, and F. Psarommatis, "A toolbox for the design, planning and operation of manufacturing networks in a mass customisation environment," J. Manuf. Syst., vol. 36, pp. 274-286, 2015.

13. M. L. Pinedo, Scheduling Theory, Algorithms, and Systems, Fifth edit. New York: Springer International Publishing, 2016. 